\title{
Design of an Open-Source Monitoring System for Thermodynamic Analysis of Buildings and Systems ${ }^{+}$
}

\author{
María de Castro ${ }^{1}$, Ivan Felis ${ }^{2, *}$, Constantino Torregrosa ${ }^{1}$, Jorge Otero ${ }^{1}$ and Sina Ellesser ${ }^{1}$ \\ 1 Univesitat Politècnica de València (UPV), Escola Politècnica Superior de Gandia (EPSG), Gandia, \\ 46730 València, Spain; madecas4@epsg.upv.es (M.de C.); ctorregr@fis.upv.es (C.T.); \\ jorotve@epsg.upv.es (J.O.); siel1@epsg.upv.es (S.E.) \\ 2 Centro Tecnológico Naval y el Mar (CTN), Fuente Álamo, 30320 Murcia, Spain \\ * Correspondence: ivanfelis@ctnaval.com; Tel.: +34-968-197-521 \\ + Presented at the 5th International Electronic Conference on Sensors and Applications, 15-30 November \\ 2018; Available online: https://ecsa-5.sciforum.net.
}

Published: 14 November 2018

\begin{abstract}
The purpose of this project was to design and implement an autonomous system based on Arduino to monitor environmental parameters that intervene in the perception of human comfort such as temperature, humidity, and solar radiation, and use them to analyze factors related to climate control and energy efficiency in buildings. The system was tested in laboratory conditions as well as by in situ measurements of building elements and living spaces. Some of the experiments carried out were contrasted with numerical simulations that allowed us to understand the implemented system.
\end{abstract}

Keywords: arduino; physical sensors; thermal monitoring; energy efficiency; building

\section{Introduction}

Nowadays, the constant development of society has increased energy consumption and its dependence on energy, with harmful effects on human beings and their environment that are reflected in environmental degradation and pollution and in the depletion of resources. To counteract these effects, it is necessary to design and construct buildings that are efficient from an energy point of view, with minimum energy consumption, but without reducing the quality of services [1-6].

The monitoring of buildings allows for the supervision and control of the parameters that intervene directly in the comfort of its users, as well as the energy that is being consumed. Thanks to this automation, energy savings and the reduction of maintenance costs would be facilitated [7].

In this text, an open-source design (Arduino based) and implementation of an autonomous system to monitor environmental parameters (such as temperature, relative humidity, or solar radiation) are described [8,9]. After the implementation, to check the correct function of the system, measurements are made in different situations, while various types of numerical simulations with different degrees of complexity are implemented to understand the thermodynamic behavior of the systems under study. Thus, the system is applied to the following cases:

- Calibration of sensors under controlled laboratory conditions. In this case, the parameters measured by the sensors are controlled externally, so that their values can be corrected.

- Measurements of the thermal behavior of test boxes with different thermal insulation, to determine heat transmission through radiation and conduction through different materials.

- Measurements of the thermal behavior of different housing enclosure types.

- Measurements of the relationship between solar radiation variation and temperature in a living space. 
Once the measurements have been obtained, they will be processed with the Matlab mathematical software tool and the corresponding conclusions will be obtained. This project is a first approximation of the methods that could be used in subsequent studies for the thermodynamic analysis of buildings, to forecast their consumption or energy demand.

\section{Design of the Experimental Device}

Figure 1 shows a diagram of the connection of the sensors with the Arduino board. The components of the device are an Arduino UNO board, temperature sensors DS18B20, a humidity sensor DHT22, a photoresistor GL5528, a MicroSD Card Module for data storage, and a Real Time Clock (RTC) DS3231.

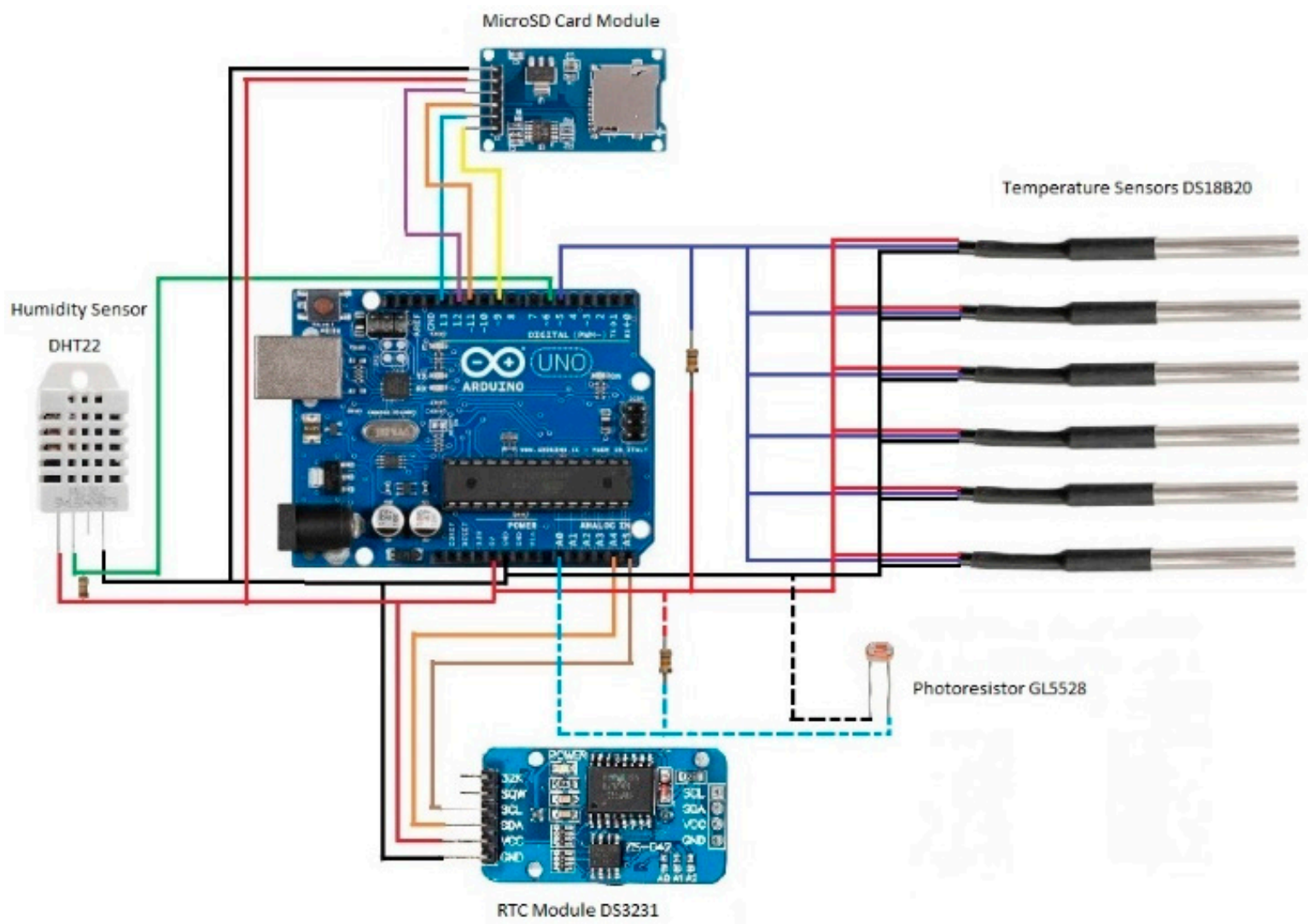

Figure 1. Electrical diagram of the thermodynamic monitoring system.

\section{Experimental Setup}

\subsection{Setup 1-Sensor Calibration}

Calibration allows for the determination of the relationship between the values obtained with this instrument and those taken as a reference. With this, the deviation and the necessary corrections can be determined. The temperature sensors have been calibrated using as reference a professional thermometer with a Testo 110 probe. The values obtained with the photoresistors or LDR (light dependent resistors) are the electrical resistance depending on the incidence of light, either artificial or natural, which increase or decrease depending on the amount of light that the resistance receives. Therefore, it is also necessary to calibrate these sensors to determine the equivalence of this resistance, measured in ohms $(\Omega)$, with respect to a unit of measurement of illuminance. In this case, a Testo 540 luxmeter is used, which measures the luminous intensity per square meter, the unit of which is the lux. 


\subsection{Setup 2-Test Boxes}

For the first test outside the laboratory, two cubes of different materials were used, see Figure 2. These measurements were carried out on the roof of a building for $24 \mathrm{~h}$ using six temperature sensors and four photoresistors. Two of the temperature sensors were placed inside the cube and the other four outside, which were distributed between the upper face, the east-facing face, the west-facing face, and the south-facing face. Next to each temperature sensor, four photoresistors were also placed to measure the light received by each one of the surfaces of the cube. The interest in these measurements resides in the fact that the simple geometry of these boxes allows their study with numerical simulation in order to contrast the experimental results with the simulations, to compare the temperature measured outside and inside each of the boxes with that obtained in the simulation.
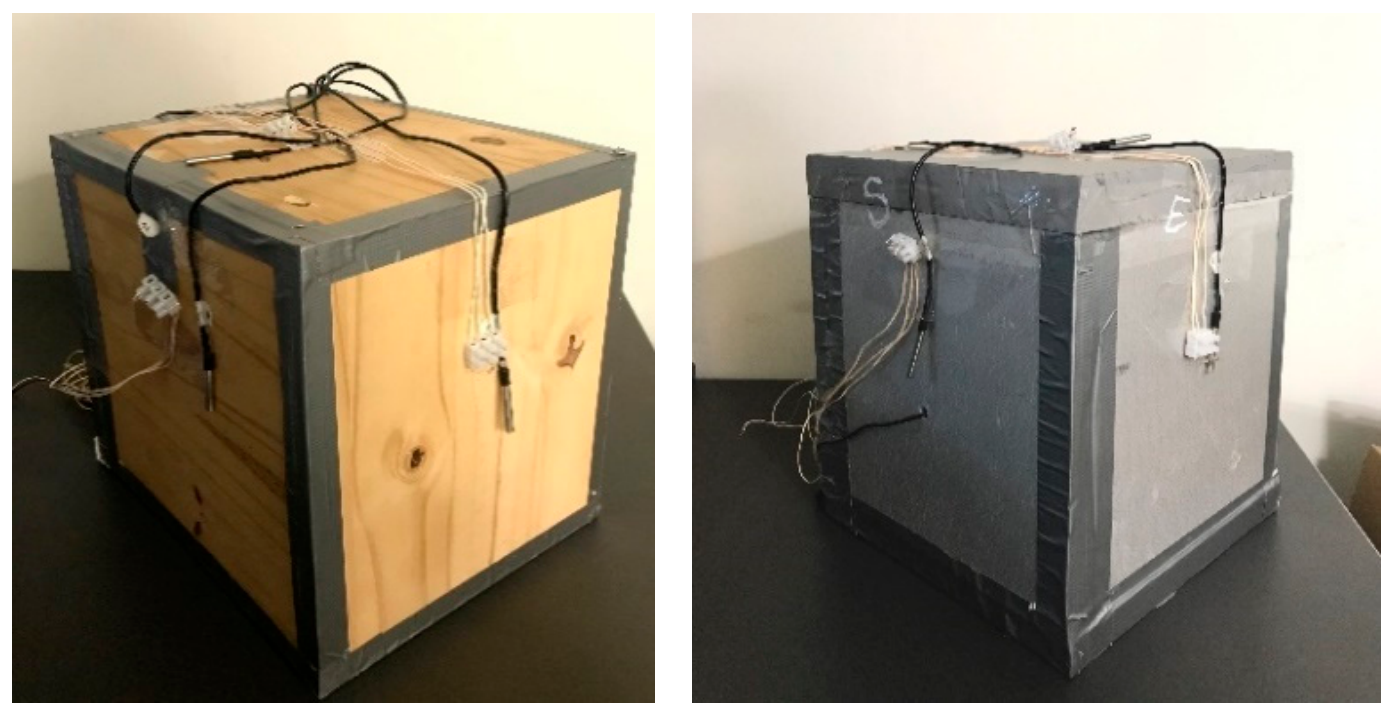

Figure 2. On the left, box of pine wood; on the right, box of polystyrene.

\subsection{Setup 3-Measurement of the Housing Envelope}

The next step was to measure the construction elements of a single-family house located in Guadarrama (Madrid) for 24-h periods, see Figure 3.

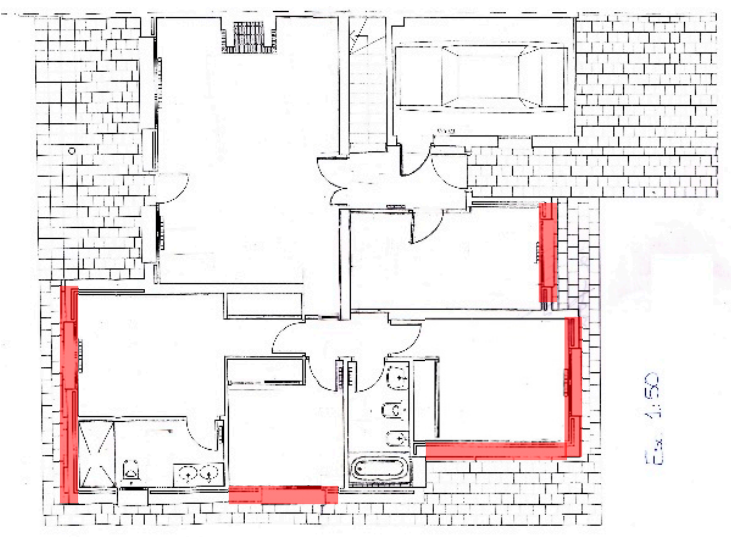

Figure 3. Plan of the wall under study.

\subsection{Setup 4-Measurement of Habitable Space}

Subsequently, solar radiation and room temperature were also measured in the Student Residence of Gandia (Valencia), in one of the rooms of Block Y, see Figure 4. 


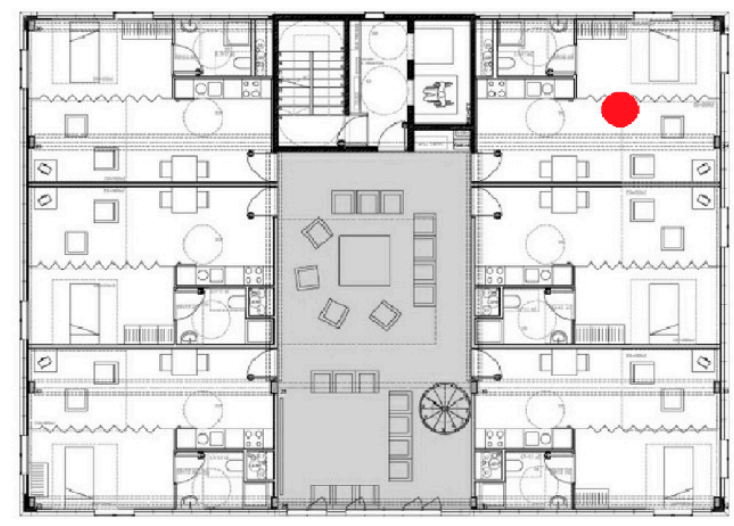

Figure 4. Plan of one floor of the Student Residence. The room space under study is marked.

\section{Results and Discussion}

\subsection{Setup 1-Sensor Calibration}

Figure 5 shows the result of the calibration of the temperature sensors $\left(\mathrm{S}_{\mathrm{i}}\right)$. The differences are generally within an interval of only a half Celsius degree in the operating temperature range used.
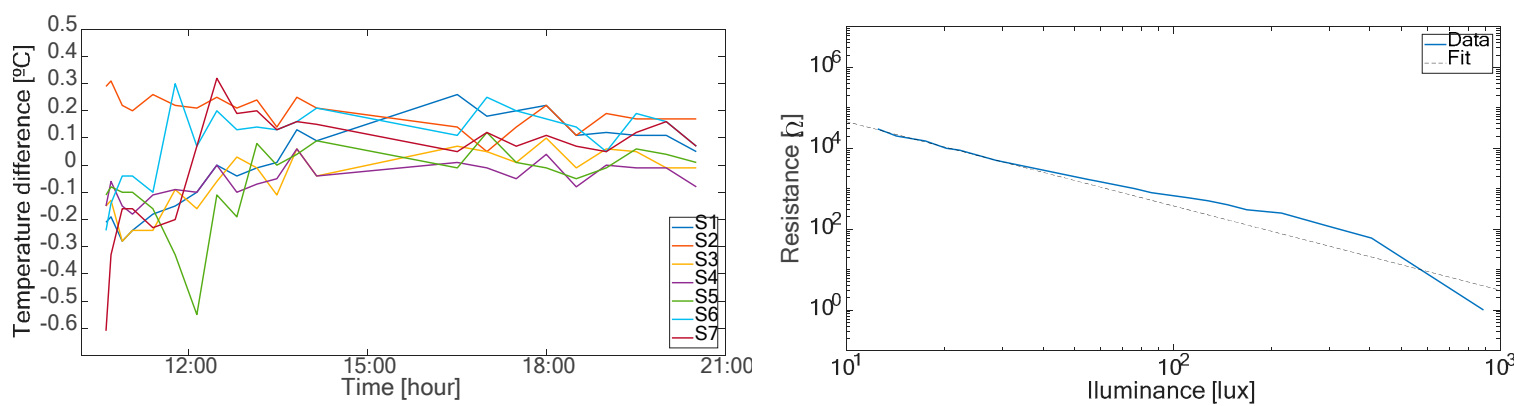

Figure 5. Difference between the value of each sensor and the reference thermometer (left). Relation between resistance (right, blue line) and illuminance on a photoresistor and a linear fit (right, dotted line).

For the calibration of the photoresistors, the lecture of a calibrated luxmeter and the output electrical resistance of the photoresistors were used. Figure 5 shows these results and a least squares linear fit given by: $x=5.5715 \times 10^{6} \cdot y^{-2.0864}$., where $x$ is the luxes and $y$ the resistance.

\subsection{Setup 2-Test Boxes}

Figure 6 shows the temperatures of the two test boxes by experimental measurements and some simulations considering similar incident radiation. It is observed that the numerical method presents a good similarity with the experimental results [10-13].
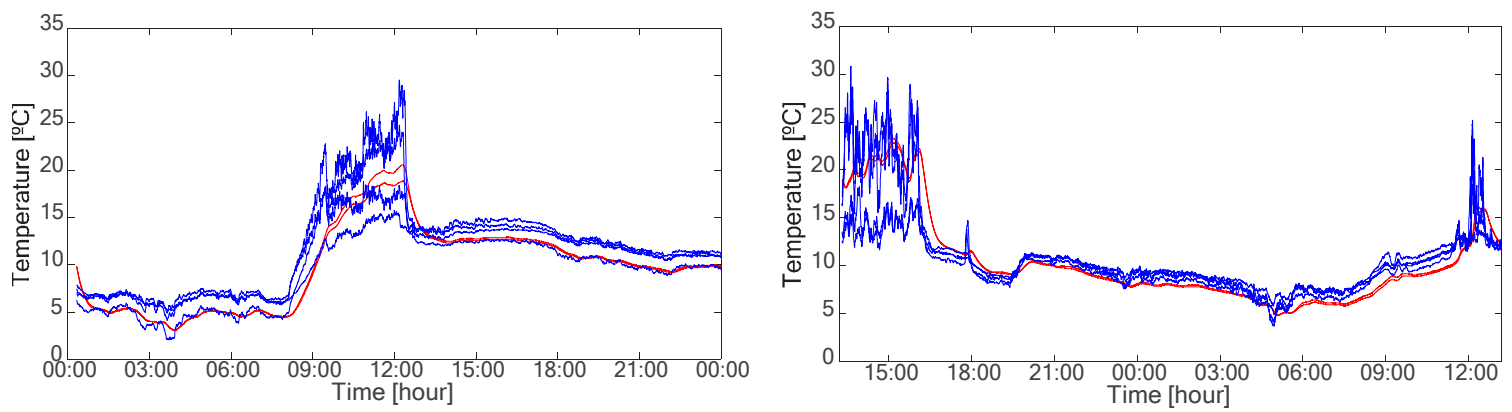

Figure 6. Temperatures obtained in situ (blue line) and by simulating with COMSOL (red line). Results of the wood box (left). Results of the polystyrene box (right). 


\subsection{Setup 3-Measurement of the Housing Envelope}

The measurements were performed on the walls oriented to the east and south, and on the windows oriented to the east, west and south, both with the blinds up and down. In Figure 7, the results obtained from the east wall are shown as an example. Indoor and outdoor temperatures from each sensor and the mean values and the relation between mean outdoor temperatures and the incident heat flux is shown.
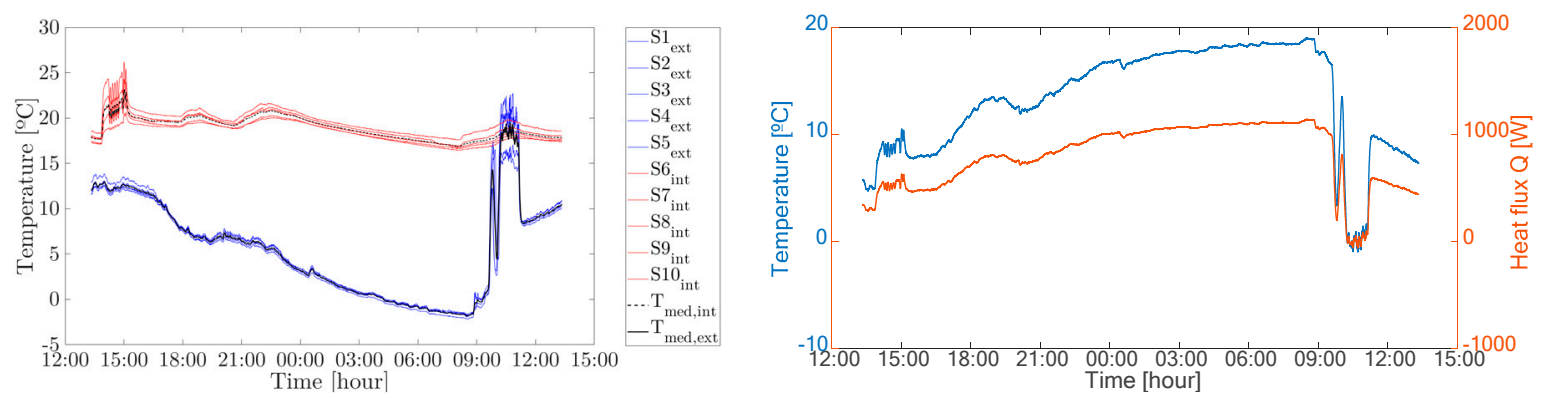

Figure 7. East wall results. On the left, temperatures obtained inside (blue) and outside (red). On the right, heat flow (orange) and temperature (light blue).

With the whole data for every wall, Table 1 shows the heat flow lost by each of the construction elements from the temperature difference measured indoors and outdoors, as well as the area A of each one and the thermal properties (thermal transmittance $\mathrm{U}\left[\mathrm{W} / \mathrm{m}^{2} \mathrm{~K}\right]$ ).

Table 1 demonstrates the capacity of a low-cost monitoring system for the real-time control of the thermal envelope of a house. With this, it is clear the saving possibilities that these systems can contribute as a part of a domotic system of a home or, simply, to help the user to take the best saving measures.

Table 1. Characteristics and results of each construction element.

\begin{tabular}{|c|c|c|c|c|c|c|c|}
\hline \multirow[b]{2}{*}{ Orientation } & \multirow{2}{*}{\multicolumn{2}{|c|}{ Construction element }} & \multicolumn{5}{|c|}{ Characteristics } \\
\hline & & & $\begin{array}{c}A \\
{\left[\mathrm{~m}^{2}\right]}\end{array}$ & $\begin{array}{c}U \\
{\left[\mathrm{~W} / \mathbf{m}^{2} \mathrm{~K}\right]}\end{array}$ & $\begin{array}{c}\dot{Q}_{\text {med }} \\
{[\mathrm{W}]}\end{array}$ & $\begin{array}{c}\boldsymbol{\delta} \dot{\boldsymbol{Q}} \\
{[\mathrm{W}]}\end{array}$ & $\begin{array}{c}Q \\
{[\mathrm{~kW} \cdot \mathrm{h}]}\end{array}$ \\
\hline \multirow{3}{*}{ East } & \multicolumn{2}{|c|}{ Wall } & 26.2 & 1.4 & 658.0 & 240.8 & 14.33 \\
\hline & \multirow{2}{*}{ Window } & Blind up & \multirow{2}{*}{3.7} & \multirow{2}{*}{2.6} & 132.8 & 18.7 & 2.1 \\
\hline & & Blind down & & & 45.5 & 3.3 & 0.9 \\
\hline \multirow{3}{*}{ South } & \multicolumn{2}{|c|}{ Wall } & 30.3 & 1.4 & 502.5 & 533.4 & 10.9 \\
\hline & Window & Blind up & \multirow{2}{*}{2.1} & \multirow{2}{*}{2.6} & 28.3 & 24.8 & 0.6 \\
\hline & villicuow & Blind down & & & 56.3 & 4.6 & 1.2 \\
\hline \multirow{4}{*}{ West } & \multicolumn{2}{|c|}{ Wall } & 26.4 & 1.4 & 624.3 & 228.5 & 13.6 \\
\hline & \multirow{2}{*}{ Window } & \multirow{3}{*}{$\begin{array}{l}\text { Blind up } \\
\text { Blind down }\end{array}$} & \multirow{2}{*}{5.6} & \multirow{2}{*}{2.6} & 164.8 & 48.0 & 3.1 \\
\hline & & & & & 57.6 & 12.2 & 1.3 \\
\hline & & & & Total & 2270.2 & 1114.5 & 48.5 \\
\hline
\end{tabular}

\subsection{Setup 4-Measurement of Habitable Space}

Figures 8 and 9 show both indoor temperatures and illuminances in the two studied spaces. The different lines represent the data of different sensors. Despite some variations and fluctuations, the mean values are tolerable. Some terminal effects can also be seen due to the thermal gap between the solar incidence (heat input) and the increase in temperature. 

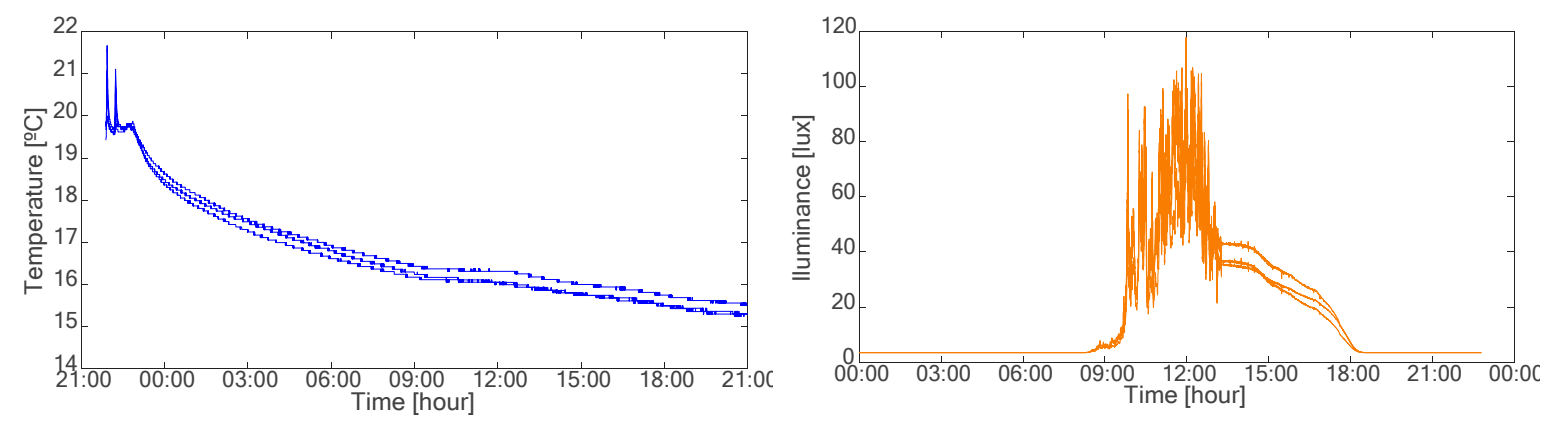

Figure 8. Results of the room oriented to the east of the house in study: temperature variation (left) and variation of luminous intensity (right).
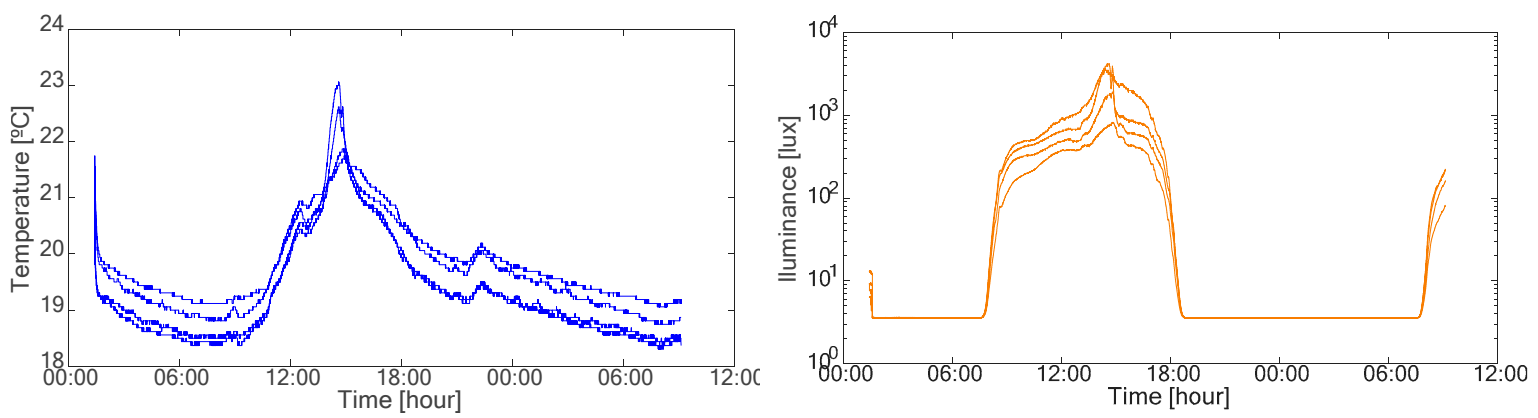

Figure 9. Results of the room of the Student Residence: Temperature variation (left) and variation of luminous intensity (right).

\section{Conclusions}

The study proposed in this work focused on designing and implementing a monitoring and control system of some of the environmental parameters that intervene in the perception of human comfort such as temperature, humidity, and lighting, and in using that data for the analysis of parameters related to air conditioning and energy efficiency in buildings. In terms of design and implementation, it has been possible to develop a prototype of an automatic system with different sensors to monitor temperature, humidity, and solar radiation data using Arduino.

After the development of the system and with respect to the measurements carried out, the calibration of the thermal and optical sensors was carried out by comparing them with standard temperature and illuminance probes in the laboratory. The result of this calibration served as a basis for adjusting the measurements and controlling any possible errors due to the use of the sensors. Preliminary measurements have been made in systems that simulate enclosures, with walls of different thermal conductivities, for comparison with computer simulations. Subsequently, measurements have been made in situ, under real environmental conditions, outside the laboratory, and these measurements have been contrasted with a thermodynamic simulation tool for a cube, presenting the results of these measurements in the form of index cards. In addition, the heat fluxes of the housing envelope have been measured and extracted, to later determine the energy efficiency of a building. Despite some setbacks in the development of the device, the final results were sufficient and adequate to perform the evaluation that was intended.

With the use of the system in real conditions and its calibration, its practicality and good working operation have been demonstrated. The result of this work can be, therefore, the basis of an interesting alternative to systems for recording and monitoring thermodynamic variables in the field of architecture and energy efficiency for its versatility and economy.

Author Contributions: Conceptualization, I.F.; methodology, I.F. and C.T.; software, M.D.C., I.F. and J.O.; validation, M.D.C. and S.E.; writing, M.D.C. and I.F.; writing-revision, C.T., J.O. and S.E.

Conflicts of Interest: The authors declare no conflict of interest. 


\section{References}

1. Felis, I. Hacia una parametrización de la arquitectura modular y sostenible. Ponencia en Escuela Técnica Superior de Arquitectura de Valencia (UPV), 2010.

2. Boronat Montilla, S. Propuesta de ahorro, mejora de la eficiencia y producción energetica para una Vivienda. Ph.D. Thesis, Universitat Politècnica de València, València, Spain, 2014.

3. IDEA - Instituto para la Diversificación y ahorro de la Energía. Available online: https://goo.gl/vGFdDH (accessed on 4 February 2018).

4. Aranda, A.; Zabalza, I. Eficiencia Energética en instalaciones y equipamiento de edificios; Prensas Universitarias de Zaragoza: Zaragoza, Spain, 2010.

5. Directiva 2010/31/UE del Parlamento Europeo y del Consejo. Available online: https://goo.gl/dzWdRG (accessed on 4 February 2018).

6. Energy Efficiency in Buildings. Available online: https://goo.gl/T7x3qF (accessed on 4 February 2018).

7. Ecured (Hardware Libre). Available online: https://goo.gl/TcBu91 (accessed on 4 February 2018).

8. Cuesta Gómez, M. Sistema de monitorización basado en hardware open source para la caracterización de células fotovoltaicas; Trabajo de Fin de Grado; Universidad de Cantabria: Cantabria, Spain, 2014.

9. Arduino (Electrontools). Available online https://goo.gl/B7JFRE (accessed on 4 February 2018).

10. Rodríguez Álvaro, R. Estudio comparativo entre métodos de evaluación de transmitancia térmica en cerramientos opacos de edificios existentes, cálculo teórico, analísis termoflujométrico, análisis termométrico y análisis cuantitativo mediante termografía infrarroja. Master's Thesis, Universidad de Sevilla, Sevilla, Spain, 2016.

11. Calor y Frio. Available online: https://goo.gl/NZTpja (accessed on 4 February 2018).

12. Gestion técnica y energética de edificios. Available online: https://goo.gl/6BsK1X (accessed on 4 February 2018).

13. Caracteristicas térmicas de los materiales. Available online: https://goo.gl/TvVoTF (accessed on 4 February 2018). 